\title{
Positive End-Expiratory Pressure Effect of 3 High-Flow Nasal Cannula Devices
}

\author{
Jing-chao Luo MD, Mei-shan Lu RN, Zhi-hong Zhao MD, Wei Jiang MD, Biao Xu MD, \\ Li Weng MD, Tong Li MD, and Bin Du MD
}

\begin{abstract}
BACKGROUND: High-flow nasal cannula (HFNC) is supposed to provide additional PEEP compared with conventional oxygen therapy. However, the exact determinants of this PEEP effect are unclear. We investigated the factors that might affect the PEEP and compared PEEP performance among 3 HFNC devices. METHODS: Three available HFNC devices were evaluated: the AIRVO 2 device and 2 mechanical ventilators (SV300 and Monnal T75). A device consisting of a test lung (5600i) and an airway model (AMT(IE)) was used to simulate spontaneous breathing. The flows ranged from 0 to their maximum flow with an interval of $10 \mathrm{~L} / \mathrm{min}$. The pressures were measured at 4 sites (nasopharynx, supraglottis, carina, and lung) under compliances of 50 and $100 \mathrm{~mL} / \mathrm{cm} \mathrm{H}_{2} \mathrm{O}$ and tidal volume of 300,500 , and $700 \mathrm{~mL}$ with the mouth closed or open. The influencing factors were determined by multiple linear regression. The sum of squares reduction test was used to compare working curves of PEEP effect among 3 devices. Pairwise comparisons were conducted by using Tukey's multiple comparisons test within an overlap of flow from 0 to $50 \mathrm{~L} / \mathrm{min}$. RESULTS: A quadratic curved relationship between PEEP and flow was observed (coefficients were $8.97 \times 10^{-3}$ for flow and $4.79 \times 10^{-4}$ for a quadratic element of flow, respectively) but evanished when the mouth was open. The PEEP increased along with lung compliance (coefficient was $2.58 \times 10^{-3}$ ). Despite the difference in working curves, both the mechanical ventilators performed slightly better than the AIRVO 2 device at higher flows (40 and $50 \mathrm{~L} / \mathrm{min}$ ). CONCLUSIONS: The mouth status, flow, and compliance were the 3 major influencing factors of PEEP effect, whereas performance of the $\mathbf{2}$ mechanical ventilators was slightly superior to that of the AIRVO 2 device at higher flows. Key words: PEEP effect; HFNC device; AIRVO 2 system; ventilator. [Respir Care 2017;62(7):888-895. (C) 2017 Daedalus Enterprises]
\end{abstract}

\section{Introduction}

High-flow nasal cannula (HFNC) oxygen therapy has become a promising novel approach of respiratory support

Drs Luo, Jiang, $\mathrm{Xu}$, Weng, and $\mathrm{Du}$ and $\mathrm{Ms} \mathrm{Lu}$ are affiliated with the Medical Intensive Care Unit, Peking Union Medical College Hospital, Beijing, China. Dr Zhao is affiliated with the Department of Clinical Medicine, Peking Union Medical College, Beijing, China. Dr Li is affiliated with the Department of Critical Care Medicine, Beijing Tongren Hospital, Capital Medical University, Beijing, China.

The authors have disclosed no conflicts of interest.

Correspondence: Bin Du MD, Medical Intensive Care Unit, Peking Union Medical College Hospital, 1 Shuai Fu Yuan, Beijing 100730, China. E-mail: dubin98@gmail.com.

DOI: $10.4187 /$ respcare.05337 in clinical settings. Multiple physiological benefits have been demonstrated, such as providing stable inspiratory oxygen concentration, ${ }^{1}$ washing out dead space, ${ }^{2,3}$ reducing work of breathing, ${ }^{4}$ sufficient humidification, ${ }^{5}$ and PEEP effect. ${ }^{6,7}$ Previous studies have shown that HFNC performs better than conventional oxygen therapy ${ }^{8,9}$ and is comparable to noninvasive ventilation support in patients with moderate respiratory failure or risk of reintubation. ${ }^{10,11}$

The advantage of HFNC over conventional oxygen therapy may be partially attributed to PEEP effect.8,12 The flow, which is associated with additional expiratory resistance and residual capacity, is considered the major determinant of PEEP. Since it is almost impossible to measure pressures in the lung directly, investigators have taken nasopharynx or tracheostomy pressure as an alternative. ${ }^{6,7,9,13-15}$ Groves et al ${ }^{6}$ reported an average expiratory 
pharyngeal pressure increment of $0.8 \mathrm{~cm} \mathrm{H}_{2} \mathrm{O} / 10 \mathrm{~L} / \mathrm{min}$ in healthy volunteers. Parke et $\mathrm{al}^{7,9}$ confirmed a similar pressure-flow relationship in elective cardiac surgery subjects. However, a computed simulation ${ }^{16}$ reported a slightly different quadratic relationship between flow and PEEP, which suggested that air flow played a more important role in the development of PEEP. Moreover, the impact of other factors (such as tidal volume $\left[\mathrm{V}_{\mathrm{T}}\right]$, lung compliance, or airway resistance) on the PEEP level remains to be elucidated. ${ }^{8}$

HFNC can be delivered through a special device (Optiflow system, Fisher \& Paykel Healthcare, Auckland, New Zealand) comprising a humidifier and an oxygen/air blender or a more advanced device (AIRVO 2 system, Fisher \& Paykel Healthcare, Auckland, New Zealand) with an independent air compressor and humidifier. In the last few years, some manufacturers have installed the HFNC module under standby mode in conventional ventilators, taking advantage of the more stable and manageable air source of these conventional ventilators. The aim of the present study is to compare the effect of different HFNC devices (the AIRVO 2 system and 2 conventional ventilators) on PEEP level by using a respiratory simulation system. In addition, the impact of different clinical settings (eg, mouth status, $\mathrm{V}_{\mathrm{T}}$, and lung compliance) on the PEEP level was also investigated.

\section{Methods}

\section{HFNC Devices}

Three HFNC devices, including the AIRVO 2 (Fisher \& Paykel Healthcare, Auckland, New Zealand) and 2 ventilators (SV300, Mindray Medical International, Shenzhen, China; Monnal T75, Air Liquide, Paris, France), were evaluated. The AIRVO 2 system, equipped with an MR290 auto-fill humidification chamber, a heated breathing tube, and an OPT844 nasal cannula of medium size that matched the size of the manikin, was set at $37^{\circ} \mathrm{C} . .^{5}$ Both ventilators were set at high-flow oxygen therapy mode and connected to an MR850 heated humidifier, an MR290 auto-fill humidification chamber, an RT202 heated breathing tube, and an OPT844 nasal cannula interface. The MR850 heated humidifier was set at invasive mode $\left(40^{\circ} \mathrm{C} /-3\right) .{ }^{5}$ For each device, $\mathrm{F}_{\mathrm{IO}_{2}}$ was set at $21 \%$, and flow was set from 0 to its upper limit (60 L/min for AIRVO 2; $50 \mathrm{~L} / \mathrm{min}$ for SV300; $80 \mathrm{~L} / \mathrm{min}$ for Monnal T75) with an interval of $10 \mathrm{~L} / \mathrm{min}$.

\section{Spontaneous Breath Simulation}

Spontaneous breath was simulated using a ventilator (G5, Hamilton Medical, Bonaduz, Switzerland), a test lung (5600i, Michigan Instruments, Grand Rapids, Michigan), and an airway model (AMT(IE), Laerdal Medical,

\section{QUICK LOOK}

\section{Current knowledge}

High-flow nasal cannula (HFNC), a promising noninvasive access for respiratory support, is considered to be associated with a beneficial PEEP effect. Flow and mouth status are 2 major determents of this PEEP effect.

\section{What this paper contributes to our knowledge}

The flow presented a non-linear relationship with PEEP with the mouth closed. The lung compliance, rather than the $\mathrm{V}_{\mathrm{T}}$, was positively correlated with the PEEP. The PEEP effects of different HFNC devices were clinically comparable with each other. The mouth status exhibited a switch effect on PEEP.

Stavanger, Norway). As shown in Figure 1, one compartment was connected to the ventilator to simulate chest wall movement (the muscle), and another parallel compartment (the lung) was connected to a resistance tube of $5 \mathrm{~cm} \mathrm{H}_{2} \mathrm{O} / \mathrm{L} / \mathrm{s}^{5}$ and then the carina of the airway model. The driving ventilator was set at volume control mode, with a frequency of 20 breaths/min; inspiratory time of $1 \mathrm{~s}$; and $\mathrm{V}_{\mathrm{T}}$ of 300,500 , or $700 \mathrm{~mL}$ without any PEEP. The compliance of the test lung was set at 50 and $100 \mathrm{~mL} / \mathrm{cm} \mathrm{H}_{2} \mathrm{O}$, respectively.

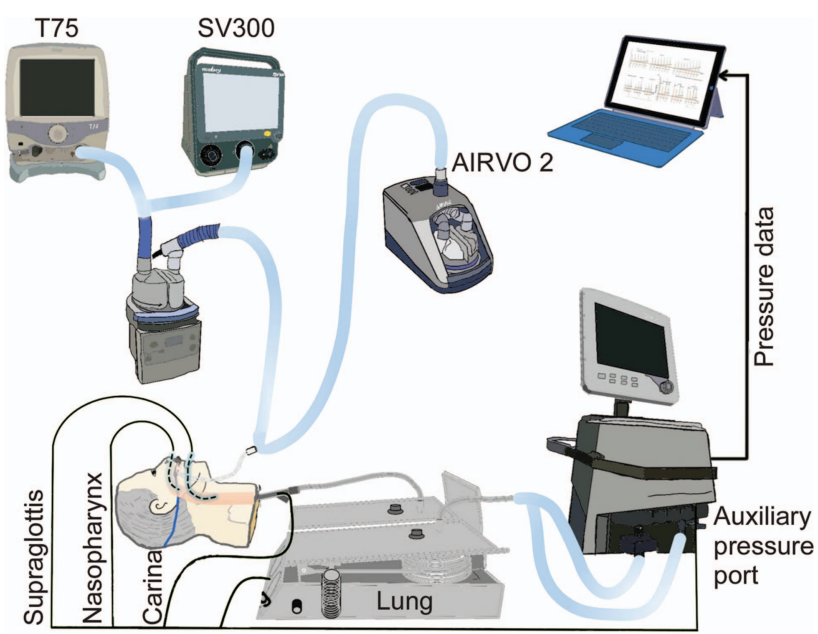

Fig. 1. A ventilator and test lung (which connected to an airway model) were used to simulate spontaneous breathing. Three highflow nasal cannula devices (AIRVO 2, SV300, and Monnal T75) with the same nasal interface were used to apply high-flow oxygen therapy. Pressure waveforms were collected at 4 sites (nasopharynx, supraglottis, carina, and lung) through lines connected to the auxiliary pressure port of the driving ventilator. 

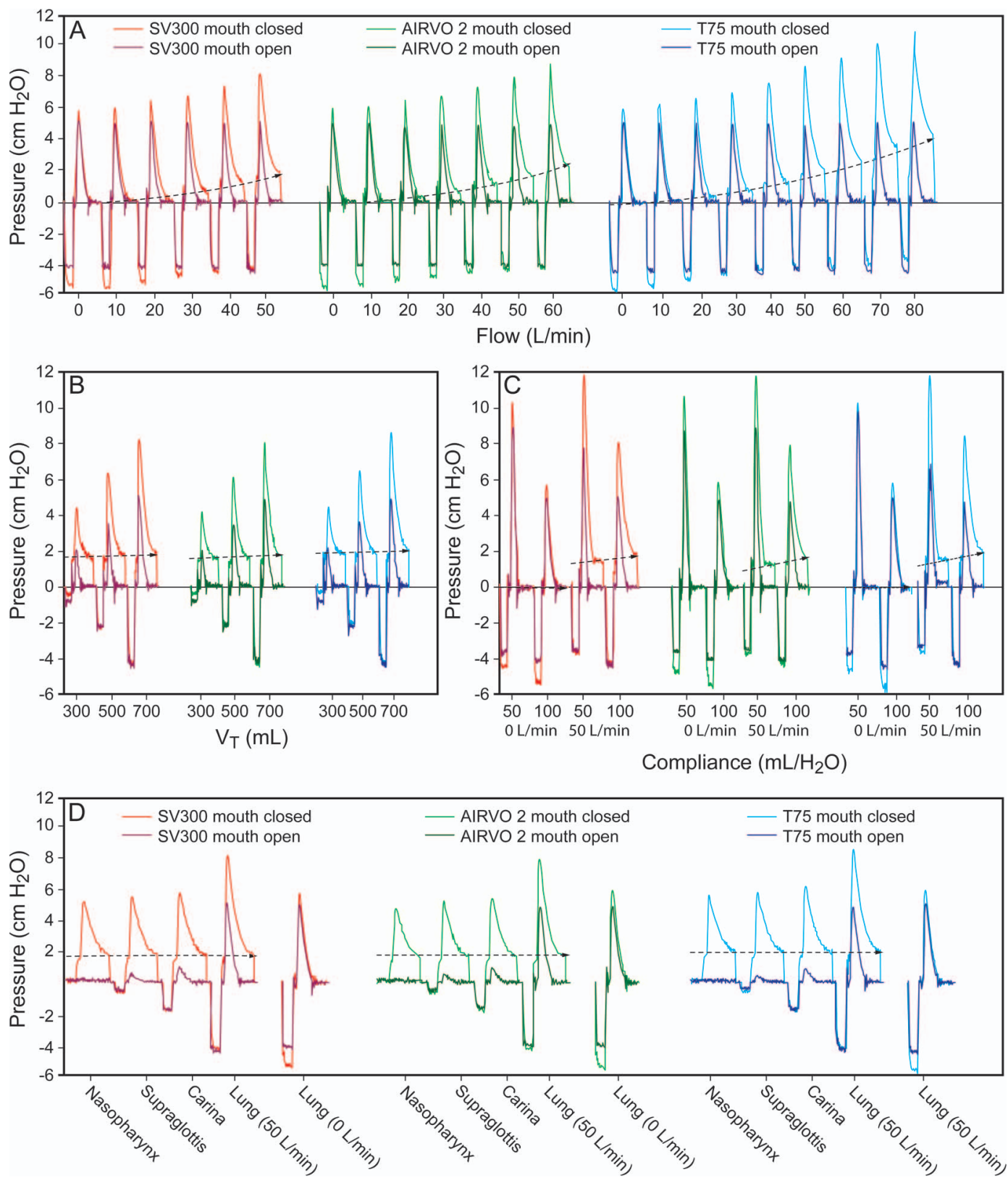

Fig. 2. A: PEEP level presented a non-linear increase with increasing flow among all 3 of the HFNC devices with the mouth closed. When the mouth was open, the PEEP effect disappeared. B: Despite the difference in tidal volume, the PEEP levels were almost the same. C: PEEP levels were slightly affected by lung compliance when the mouth was closed. D: PEEP levels measured at the nasopharynx, supraglottis, carina, and lung were extremely close.

\section{Pressure Measurements}

Three pressure catheters (DPT-248, Utah Medical Products, Midvale, Utah) were inserted at the nasopharynx, supraglottis, and carina of the airway model, and another was connected to the lung compartment (Fig. 1). The positions of catheter tips were confirmed by fiber bronchoscopy. These lines were connected to the auxiliary pressure port of the G5 ventilator to record pressure waveform data.

\section{Study Protocol}

The HFNC nasal cannula was inserted into the nostrils of the airway model. The pressure was measured at different settings of mouth status (closed or open), $\mathrm{V}_{\mathrm{T}}$ $(300,500$, or $700 \mathrm{~mL})$, compliance $(50$ or $100 \mathrm{~mL} / \mathrm{cm}$ $\left.\mathrm{H}_{2} \mathrm{O}\right)$, and flow $(0,10,20,30,40,50$, or $60 \mathrm{~L} / \mathrm{min}$ for the AIRVO 2; $0,10,20,30,40$, or $50 \mathrm{~L} / \mathrm{min}$ for the SV300; 0, 10, 20, 30, 40, 50, 60, 70, or $80 \mathrm{~L} / \mathrm{min}$ for the 
Table 1. PEEP Effect of 3 High-Flow Nasal Cannula Devices With Mouth Closed

\begin{tabular}{|c|c|c|c|c|c|c|}
\hline \multirow{2}{*}{ Flow (L/min) } & \multicolumn{3}{|c|}{ Compliance $=50 \mathrm{~mL} / \mathrm{cm} \mathrm{H}_{2} \mathrm{O}$} & \multicolumn{3}{|c|}{ Compliance $=100 \mathrm{~mL} / \mathrm{cm} \mathrm{H}_{2} \mathrm{O}$} \\
\hline & $\mathrm{V}_{\mathrm{T}}=300 \mathrm{~mL}$ & $\mathrm{~V}_{\mathrm{T}}=500 \mathrm{~mL}$ & $\mathrm{~V}_{\mathrm{T}}=700 \mathrm{~mL}$ & $\mathrm{~V}_{\mathrm{T}}=300 \mathrm{~mL}$ & $\mathrm{~V}_{\mathrm{T}}=500 \mathrm{~mL}$ & $\mathrm{~V}_{\mathrm{T}}=700 \mathrm{~mL}$ \\
\hline \multicolumn{7}{|l|}{ SV300 } \\
\hline 0 & $-0.01 \pm 0.04$ & $0.01 \pm 0.03$ & $-0.01 \pm 0.03$ & $-0.03 \pm 0.01$ & $0.01 \pm 0.03$ & $-0.01 \pm 0.03$ \\
\hline 10 & $0.07 \pm 0.03$ & $0.06 \pm 0.04$ & $0.08 \pm 0.04$ & $0.08 \pm 0.02$ & $0.08 \pm 0.02$ & $0.09 \pm 0.02$ \\
\hline 20 & $0.24 \pm 0.03$ & $0.27 \pm 0.02$ & $0.26 \pm 0.03$ & $0.30 \pm 0.02$ & $0.29 \pm 0.03$ & $0.29 \pm 0.02$ \\
\hline 30 & $0.62 \pm 0.03$ & $0.60 \pm 0.03$ & $0.60 \pm 0.03$ & $0.62 \pm 0.02$ & $0.68 \pm 0.03$ & $0.71 \pm 0.03$ \\
\hline 40 & $1.05 \pm 0.02$ & $1.02 \pm 0.03$ & $1.01 \pm 0.02$ & $1.10 \pm 0.04$ & $1.20 \pm 0.02$ & $1.22 \pm 0.02$ \\
\hline 50 & $1.56 \pm 0.03$ & $1.56 \pm 0.03$ & $1.54 \pm 0.04$ & $1.67 \pm 0.03$ & $1.71 \pm 0.09$ & $1.74 \pm 0.03$ \\
\hline \multicolumn{7}{|l|}{ AIRVO 2} \\
\hline 0 & $-0.01 \pm 0.04$ & $0.00 \pm 0.03$ & $0.00 \pm 0.03$ & $0.01 \pm 0.03$ & $-0.01 \pm 0.03$ & $-0.02 \pm 0.02$ \\
\hline 10 & $0.10 \pm 0.03$ & $0.07 \pm 0.03$ & $0.09 \pm 0.04$ & $0.09 \pm 0.02$ & $0.11 \pm 0.03$ & $0.08 \pm 0.05$ \\
\hline 20 & $0.32 \pm 0.02$ & $0.32 \pm 0.02$ & $0.36 \pm 0.02$ & $0.35 \pm 0.03$ & $0.33 \pm 0.03$ & $0.34 \pm 0.03$ \\
\hline 30 & $0.63 \pm 0.02$ & $0.64 \pm 0.02$ & $0.62 \pm 0.03$ & $0.63 \pm 0.04$ & $0.63 \pm 0.04$ & $0.64 \pm 0.03$ \\
\hline 40 & $0.97 \pm 0.03$ & $0.98 \pm 0.02$ & $0.98 \pm 0.03$ & $1.05 \pm 0.05$ & $1.06 \pm 0.04$ & $1.15 \pm 0.03$ \\
\hline 50 & $1.42 \pm 0.05$ & $1.40 \pm 0.03$ & $1.33 \pm 0.04$ & $1.59 \pm 0.02$ & $1.59 \pm 0.03$ & $1.70 \pm 0.06$ \\
\hline 60 & $1.86 \pm 0.02$ & $1.83 \pm 0.02$ & $1.82 \pm 0.02$ & $2.27 \pm 0.03$ & $2.29 \pm 0.03$ & $2.43 \pm 0.04$ \\
\hline \multicolumn{7}{|l|}{ Monnal T75 } \\
\hline 0 & $0.00 \pm 0.04$ & $0.01 \pm 0.02$ & $0.00 \pm 0.02$ & $-0.01 \pm 0.02$ & $-0.01 \pm 0.03$ & $0.00 \pm 0.03$ \\
\hline 10 & $0.08 \pm 0.04$ & $0.09 \pm 0.01$ & $0.07 \pm 0.01$ & $0.07 \pm 0.01$ & $0.07 \pm 0.01$ & $0.08 \pm 0.02$ \\
\hline 20 & $0.28 \pm 0.03$ & $0.28 \pm 0.01$ & $0.25 \pm 0.02$ & $0.32 \pm 0.01$ & $0.31 \pm 0.02$ & $0.31 \pm 0.03$ \\
\hline 30 & $0.65 \pm 0.04$ & $0.62 \pm 0.02$ & $0.59 \pm 0.03$ & $0.70 \pm 0.02$ & $0.66 \pm 0.03$ & $0.67 \pm 0.02$ \\
\hline 40 & $1.13 \pm 0.03$ & $1.11 \pm 0.02$ & $0.98 \pm 0.01$ & $1.32 \pm 0.02$ & $1.24 \pm 0.02$ & $1.28 \pm 0.03$ \\
\hline 50 & $1.78 \pm 0.03$ & $1.71 \pm 0.03$ & $1.61 \pm 0.02$ & $1.89 \pm 0.02$ & $1.92 \pm 0.03$ & $1.96 \pm 0.05$ \\
\hline 60 & $2.30 \pm 0.02$ & $2.25 \pm 0.02$ & $2.11 \pm 0.02$ & $2.49 \pm 0.03$ & $2.50 \pm 0.03$ & $2.58 \pm 0.07$ \\
\hline 70 & $2.90 \pm 0.03$ & $2.90 \pm 0.05$ & $2.69 \pm 0.10$ & $3.18 \pm 0.02$ & $3.13 \pm 0.02$ & $3.21 \pm 0.12$ \\
\hline 80 & $3.59 \pm 0.05$ & $3.59 \pm 0.07$ & $3.41 \pm 0.07$ & $3.90 \pm 0.03$ & $3.95 \pm 0.07$ & $4.02 \pm 0.10$ \\
\hline$v_{\mathrm{T}}=$ tidal volume & & & & & & \\
\hline
\end{tabular}

Monnal T75, depending on their maximum flow, respectively). For each setting, after stabilization for $10 \mathrm{~min}$, the pressure waveforms at each site (nasopharynx, supraglottis, carina, and lung, respectively) were recorded for $1 \mathrm{~min}$ (approximately 20 waveforms), of which 10 representative waveforms were selected upon consensus for further analysis.

\section{Statistical Analysis}

For each waveform, the PEEP was defined as the average pressure of the last $0.1 \mathrm{~s}$ of expiratory phase. Continuous variables are presented as mean \pm SD. Multiple linear regression was used to determine predictors of PEEP. The covariates that entered into the model included device type (as dummy variables), flow, compliance, and $\mathrm{V}_{\mathrm{T}}$. A quadratic element of flow $\left(\right.$ flow $^{2}$ ) was added to the model to improve model fitting. The sum of squares reduction test was performed to compare the working curves of 3 devices. Within an overlap of flow from 0 to $50 \mathrm{~L} / \mathrm{min}$, the PEEP values of 3 devices were compared through the Tukey multiple comparisons test for each level of flow.
All statistical tests were 2-sided, and $P<.01$ was considered statistically significant. All statistical analyses were performed using SPSS 17.0 (SPSS, Chicago, Illinois).

\section{Results}

The influence of different variables on PEEP is demonstrated in Figure 2 and Tables 1 and 2. When the mouth was open, PEEP level decreased rapidly to nearly zero (Table 2 and Fig. 2). Therefore, further analysis was based only on waveforms when the mouth was closed.

With the mouth closed, PEEP level exerted a non-linear increase with increasing flow (Fig. 2A), whereas it was less affected by lung compliance (Fig. 2B) and $\mathrm{V}_{\mathrm{T}}$ (Fig. $2 \mathrm{C})$. In addition, the PEEP levels measured at the nasopharynx, supraglottis, carina, and lung were clinically comparable despite a statistically significant difference (Fig. 2D). At the same setting, the PEEP levels developed by the 3 HFNC devices exhibited marginally statistically significant difference (Fig. 3).

The results of multiple linear regression are presented in Table 3, which included device type, compliance, and both 
Table 2. PEEP Effect of 3 High-Flow Nasal Cannula Devices With Mouth Open

\begin{tabular}{|c|c|c|c|c|c|c|}
\hline \multirow{2}{*}{ Flow (L/min) } & \multicolumn{3}{|c|}{ Compliance $=50 \mathrm{~mL} / \mathrm{cm} \mathrm{H}_{2} \mathrm{O}$} & \multicolumn{3}{|c|}{ Compliance $=100 \mathrm{~mL} / \mathrm{cm} \mathrm{H}_{2} \mathrm{O}$} \\
\hline & $\mathrm{V}_{\mathrm{T}}=300 \mathrm{~mL}$ & $\mathrm{~V}_{\mathrm{T}}=500 \mathrm{~mL}$ & $\mathrm{~V}_{\mathrm{T}}=700 \mathrm{~mL}$ & $\mathrm{~V}_{\mathrm{T}}=300 \mathrm{~mL}$ & $\mathrm{~V}_{\mathrm{T}}=500 \mathrm{~mL}$ & $\mathrm{~V}_{\mathrm{T}}=700 \mathrm{~mL}$ \\
\hline \multicolumn{7}{|l|}{ SV300 } \\
\hline 0 & $-0.01 \pm 0.02$ & $-0.01 \pm 0.01$ & $-0.04 \pm 0.11$ & $0.00 \pm 0.02$ & $-0.01 \pm 0.02$ & $0.00 \pm 0.02$ \\
\hline 10 & $0.01 \pm 0.01$ & $0.00 \pm 0.02$ & $0.01 \pm 0.02$ & $-0.01 \pm 0.02$ & $0.00 \pm 0.01$ & $0.01 \pm 0.02$ \\
\hline 20 & $0.01 \pm 0.02$ & $0.02 \pm 0.01$ & $0.01 \pm 0.02$ & $0.00 \pm 0.02$ & $0.02 \pm 0.02$ & $0.00 \pm 0.02$ \\
\hline 30 & $0.01 \pm 0.02$ & $0.03 \pm 0.03$ & $0.01 \pm 0.02$ & $0.02 \pm 0.02$ & $0.02 \pm 0.01$ & $0.01 \pm 0.02$ \\
\hline 40 & $0.03 \pm 0.01$ & $0.03 \pm 0.01$ & $0.02 \pm 0.02$ & $0.02 \pm 0.02$ & $0.02 \pm 0.01$ & $0.01 \pm 0.03$ \\
\hline 50 & $0.04 \pm 0.01$ & $0.06 \pm 0.01$ & $0.03 \pm 0.02$ & $0.03 \pm 0.01$ & $0.02 \pm 0.02$ & $0.03 \pm 0.02$ \\
\hline \multicolumn{7}{|l|}{ AIRVO 2} \\
\hline 0 & $0.01 \pm 0.03$ & $-0.01 \pm 0.03$ & $0.02 \pm 0.01$ & $0.00 \pm 0.02$ & $0.00 \pm 0.02$ & $0.01 \pm 0.04$ \\
\hline 10 & $0.02 \pm 0.05$ & $0.00 \pm 0.02$ & $0.01 \pm 0.02$ & $0.00 \pm 0.02$ & $0.03 \pm 0.02$ & $0.01 \pm 0.02$ \\
\hline 20 & $0.01 \pm 0.02$ & $0.00 \pm 0.02$ & $0.03 \pm 0.02$ & $0.00 \pm 0.01$ & $0.02 \pm 0.02$ & $0.00 \pm 0.02$ \\
\hline 30 & $0.02 \pm 0.03$ & $0.02 \pm 0.01$ & $0.02 \pm 0.02$ & $0.03 \pm 0.01$ & $0.01 \pm 0.03$ & $0.01 \pm 0.02$ \\
\hline 40 & $0.02 \pm 0.03$ & $0.02 \pm 0.02$ & $0.03 \pm 0.01$ & $0.00 \pm 0.01$ & $0.02 \pm 0.02$ & $0.00 \pm 0.02$ \\
\hline 50 & $0.03 \pm 0.03$ & $0.03 \pm 0.02$ & $0.05 \pm 0.01$ & $0.03 \pm 0.01$ & $0.04 \pm 0.02$ & $0.01 \pm 0.02$ \\
\hline 60 & $0.04 \pm 0.03$ & $0.03 \pm 0.03$ & $0.06 \pm 0.02$ & $0.04 \pm 0.02$ & $0.05 \pm 0.02$ & $0.05 \pm 0.02$ \\
\hline \multicolumn{7}{|l|}{ Monnal T75 } \\
\hline 0 & $-0.01 \pm 0.02$ & $0.01 \pm 0.01$ & $0.01 \pm 0.02$ & $-0.01 \pm 0.02$ & $-0.01 \pm 0.02$ & $0.00 \pm 0.02$ \\
\hline 10 & $0.02 \pm 0.02$ & $0.02 \pm 0.01$ & $0.02 \pm 0.01$ & $0.00 \pm 0.02$ & $0.00 \pm 0.02$ & $0.02 \pm 0.02$ \\
\hline 20 & $0.00 \pm 0.06$ & $0.02 \pm 0.02$ & $0.02 \pm 0.02$ & $0.01 \pm 0.01$ & $0.01 \pm 0.02$ & $0.00 \pm 0.02$ \\
\hline 30 & $0.02 \pm 0.02$ & $0.03 \pm 0.02$ & $0.02 \pm 0.02$ & $0.02 \pm 0.01$ & $0.02 \pm 0.01$ & $0.03 \pm 0.03$ \\
\hline 40 & $0.03 \pm 0.02$ & $0.03 \pm 0.01$ & $0.03 \pm 0.02$ & $0.03 \pm 0.02$ & $0.03 \pm 0.02$ & $0.04 \pm 0.02$ \\
\hline 50 & $0.04 \pm 0.01$ & $0.05 \pm 0.01$ & $0.04 \pm 0.02$ & $0.04 \pm 0.01$ & $0.04 \pm 0.03$ & $0.05 \pm 0.02$ \\
\hline 60 & $0.05 \pm 0.01$ & $0.06 \pm 0.02$ & $0.06 \pm 0.01$ & $0.06 \pm 0.02$ & $0.04 \pm 0.01$ & $0.05 \pm 0.03$ \\
\hline 70 & $0.05 \pm 0.01$ & $0.07 \pm 0.01$ & $0.06 \pm 0.01$ & $0.08 \pm 0.01$ & $0.06 \pm 0.02$ & $0.04 \pm 0.02$ \\
\hline 80 & $0.07 \pm 0.02$ & $0.07 \pm 0.02$ & $0.09 \pm 0.02$ & $0.09 \pm 0.02$ & $0.06 \pm 0.02$ & $0.08 \pm 0.02$ \\
\hline dal volume & & & & & & \\
\hline
\end{tabular}

linear and quadratic elements of flow as covariates, with perfect regression accuracy (adjusted $\mathrm{R}^{2}=0.99$ ). Moreover, among all covariates in this model, flow exhibited the most significant impact on PEEP level, as suggested by standardized coefficients. In addition, compliance has a lesser but significant impact on PEEP level, indicating that increasing compliance is associated with better PEEP level.

Comparison of the working curves of the 3 HFNC devices with the sum of squares reduction test suggested significant differences with both levels of compliance (Fig. 3 , A and B). When flow increased within an overlapped range from 0 to $50 \mathrm{~L} / \mathrm{min}$, pairwise comparison of the 3 HFNC devices suggested that, with the exception of a flow of $20 \mathrm{~L} / \mathrm{min}$, the Monnal T75 had the best general performance, followed by the SV300, and AIRVO 2 (Fig. 3, C and D). For example, with compliance of $100 \mathrm{~mL} / \mathrm{cm} \mathrm{H}_{2} \mathrm{O}$, $\mathrm{V}_{\mathrm{T}}$ of $700 \mathrm{~mL}$, and flow of $50 \mathrm{~L} / \mathrm{min}$, the PEEP level was $1.74 \pm 0.03,1.70 \pm 0.06$, and $1.96 \pm 0.05 \mathrm{~cm} \mathrm{H}_{2} \mathrm{O}$ for the SV300, AIRVO 2, and Monnal T75, respectively. Nevertheless, due to the difference in the maximum flow of the 3 HFNC devices, theoretical maximum PEEP levels were $1.74 \pm 0.03,2.43 \pm 0.04$, and $4.02 \pm 0.10 \mathrm{~cm} \mathrm{H}_{2} \mathrm{O}$ for the
SV300 (50 L/min), AIRVO 2 (60 L/min), and Monnal T75 (80 L/min), respectively, when compliance was set at $100 \mathrm{~mL} / \mathrm{cm} \mathrm{H}_{2} \mathrm{O}$ and $\mathrm{V}_{\mathrm{T}}$ was set at $700 \mathrm{~mL}$.

\section{Discussion}

To the best of our knowledge, this is the first bench study to evaluate the PEEP performance of different HFNC devices. We have found that, compared with a dedicated HFNC device (AIRVO 2 system), ventilators with a built-in high-flow module are capable of delivering similar levels of PEEP. In addition, flow exhibits the most significant impact on PEEP level in a quadratic curved relationship with the mouth closed. For the first time, we found that the PEEP levels measured at different sites (ie, nasopharynx, supraglottis, carina, and lung) were comparable, supporting the use of nasopharynx or tracheostomy pressure as a surrogate marker in previous studies. $6,7,9,13-15$

The mouth status is a major determinant for PEEP level in all 3 HFNC devices, which is in accordance with findings in healthy volunteers ${ }^{6}$ and surgical subjects. ${ }^{7,17} \mathrm{Al}-$ though the exact mechanism of the PEEP effect with HFNC devices remains to be elucidated, increased expiratory re- 

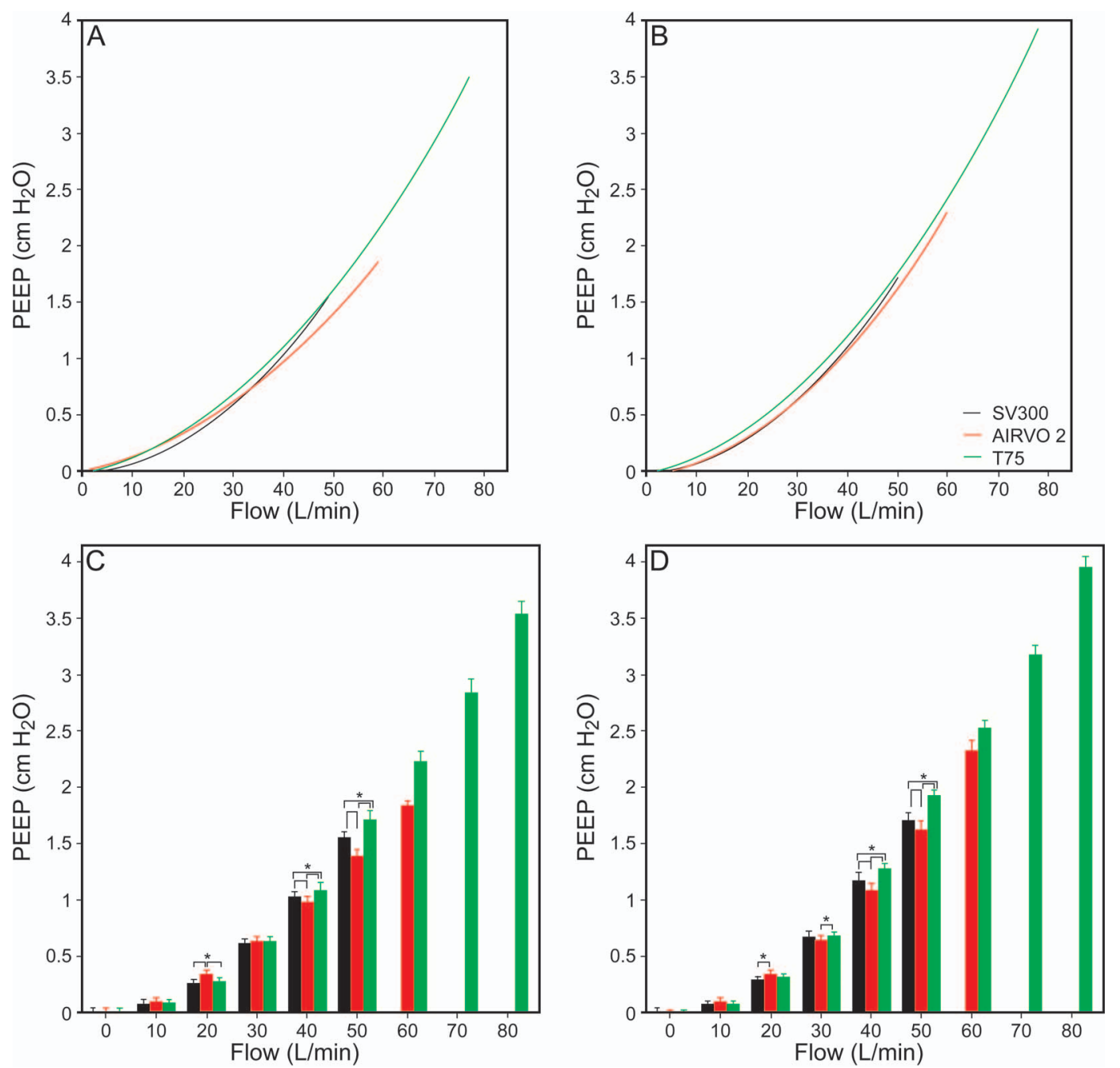

Fig. 3. A: With a compliance of $50 \mathrm{~mL} / \mathrm{cm} \mathrm{H}_{2} \mathrm{O}$, the working curves of $3 \mathrm{HFNC}$ devices were significantly different $(P<.001)$. The regression equations were PEEP $=2.2 \times 10^{-3}+$ flow $^{2}+5.8 \times 10^{-4}$ flow, PEEP $=3.4 \times 10^{-4} \times$ flow $^{2}+1.0 \times 10^{-2} \times$ flow, and PEEP $=4.5 \times 10^{-4}+$ flow $^{2}+9.3 \times 10^{-3} \times$ flow for the SV300, AIRVO 2, and Monnal T75 devices, respectively. B: With a compliance of $100 \mathrm{~mL} \mathrm{~cm} \mathrm{H}_{2} \mathrm{O}$, the working curves of 3 HFNC devices were also of statistical significance $(P<.001)$. The regression equations were PEEP $=6.3 \times 10^{-4} \times$ flow ${ }^{2}+3.2 \times$ $10^{-3} \times$ flow, PEEP $=5.7 \times 10^{-4} \times$ flow $^{2}+4.3 \times 10^{-3} \times$ flow, and PEEP $=4.9 \times 10^{-4} \times$ flow $^{2}+1.1 \times 10^{-2} \times$ flow for the SV300, AlRVO 2, and Monnal T75 devices, respectively. C: For pairwise comparison with a compliance of $50 \mathrm{~mL} / \mathrm{cm} \mathrm{H}_{2} \mathrm{O}$, with the exception of a flow of 20 L/min, Monnal T75 had the best general performance, followed by the SV300 and AIRVO 2. D: For pairwise comparison with a compliance of $100 \mathrm{~mL} / \mathrm{cm} \mathrm{H}_{2} \mathrm{O}$, the Monnal T75 still had the best general performance, followed by the SV300 and AIRVO 2. *, $P<.001$.

sistance $^{16}$ (resulting from nasal cannula and inward air flow) is believed to enlarge end-expiratory lung volume (or residual volume) ${ }^{18}$ and generate a PEEP effect. Once the mouth is open, the extra expiratory resistance would vanish immediately, and the PEEP effect would disappear in the meantime. However, previous studies in humans demonstrated a residual PEEP effect even with the mouth open, whereas we could not observe any PEEP effect with the airway model, even at a flow as high as $80 \mathrm{~L} / \mathrm{min}$, which might be attributable to a structural discrepancy of the upper airway.

Flow plays a more important role in PEEP effect than previously believed. Both Parke et $\mathrm{al}^{7,17}$ and Groves et $\mathrm{al}^{6}$ reported a linear relationship between PEEP and flow. However, based on principles of hydrodynamics, the flowresistance effect was often nonlinear, especially with high flow. ${ }^{19}$ Accordingly, Kumar et al ${ }^{16}$ first proposed the quadratic curved relationship between PEEP and flow with a computerized hydrodynamic model. Our study confirmed the above findings, suggesting a much steeper increase in PEEP level at higher flows.

We observed a significant correlation between PEEP level and lung compliance, which had not been described previously. Of note, in patients with more severe ARDS, who may benefit from high PEEP to recruit collapsed alveoli, the delivered PEEP levels by any HFNC devices 
Table 3. Multiple Linear Regression on Factors Determining the PEEP

\begin{tabular}{|c|c|c|c|c|c|}
\hline Factors & Coefficients & $95 \% \mathrm{CI}$ & Standardized Coefficients & $P$ & Tolerance \\
\hline SV300 & $-2.37 \times 10^{-1}$ & $-2.61 \times 10^{-1}$ to $-2.13 \times 10^{-1}$ & -0.085 & $<.001$ & 0.2 \\
\hline AIRVO 2 & $-2.74 \times 10^{-1}$ & $-2.98 \times 10^{-1}$ to $-2.50 \times 10^{-1}$ & -0.106 & $<.001$ & 0.2 \\
\hline Monnal T75 & $-1.79 \times 10^{-1}$ & $-2.03 \times 10^{-1}$ to $-1.56 \times 10^{-1}$ & -0.079 & $<.001$ & 0.2 \\
\hline Flow $^{2}$ & $4.79 \times 10^{-4}$ & $4.67 \times 10^{-4}$ to $4.90 \times 10^{-4}$ & 0.769 & $<.001$ & 0.0 \\
\hline Flow & $8.97 \times 10^{-3}$ & $8.12 \times 10^{-3}$ to $9.81 \times 10^{-3}$ & 0.246 & $<.001$ & 0.0 \\
\hline Compliance & $2.58 \times 10^{-3}$ & $2.35 \times 10^{-3}$ to $2.82 \times 10^{-3}$ & 0.140 & $<.001$ & 0.1 \\
\hline
\end{tabular}

are expected to be low due to reduced compliance. This downside might explain the high failure rate $(40 \%)$ of HFNC devices in this high-risk patient population as reported in a cohort study, ${ }^{20}$ suggesting cautious use of HFNC in severe ARDS.

Another objective of the present study was to compare the performance of 3 commercially available HFNC devices. Despite some statistical significance with flows of 20,40 , and $50 \mathrm{~L} / \mathrm{min}$, the difference among the 3 devices regarding PEEP level was trivial in clinical practice. Based on these findings, the flow rather than choice of different devices might be more relevant in the determination of PEEP level. Interestingly, among all 3 devices tested, the Monnal T75 ventilator had the ability to deliver a flow up to $80 \mathrm{~L} / \mathrm{min}$, which was associated with a much higher PEEP level. However, the efficacy of the humidifier at a flow of $>60 \mathrm{~L} / \mathrm{min}$ has not been well-studied.

Our study has some limitations. As a bench study, we only investigated the PEEP effect within a simulation system, which might be different from clinical subjects. However, this model coincided well with physiology and enabled us to make quantitative comparisons. In addition, we arbitrarily selected 2 levels of compliance and 3 levels of $\mathrm{V}_{\mathrm{T}}$ to investigate their impact on PEEP levels. A more accurate interpretation of their roles might be possible if more levels were selected. Moreover, the 2 levels of lung compliance (100 and $50 \mathrm{~mL} / \mathrm{cm} \mathrm{H}_{2} \mathrm{O}$ ) tested in our study represented relatively normal lung and mildly affected lung. According to our experience, patients with significantly lower compliance (ie, patients with severe respiratory failure) exhibited very poor response to HFNC. Our findings are consistent with this observation, where we observed a significant correlation between PEEP and lung compliance. Therefore, HFNC has not been recommended for severe hypoxemic acute respiratory failure. ${ }^{8}$ Furthermore, the influence of high airway resistance on PEEP level was not investigated in our study, since the benefit of HFNC in severe air-flow obstruction has not been well established. ${ }^{21}$

\section{Conclusions}

This bench study has demonstrated that mouth status, flow, and compliance are the most important determinants of PEEP effect during HFNC, whereas performance of the 2 mechanical ventilators is slightly superior to that of the AIRVO 2 device at higher flows. In contrast to previous studies, we observe no PEEP effect with the mouth open even at a flow as high as $80 \mathrm{~L} / \mathrm{min}$. However, these findings need to be confirmed in future clinical studies.

\section{REFERENCES}

1. Ritchie JE, Williams AB, Gerard C, Hockey H. Evaluation of a humidified nasal high-flow oxygen system, using oxygraphy, capnography and measurement of upper airway pressures. Anaesth Intensive Care 2011;39(6):1103-1110.

2. Möller W, Celik G, Feng S, Bartenstein P, Meyer G, Oliver E, et al. Nasal high flow clears anatomical dead space in upper airway models. J Appl Physiol 2015;118(12):1525-1532.

3. Frizzola M, Miller TL, Rodriguez ME, Zhu Y, Rojas J, Hesek A, et al. High-flow nasal cannula: impact on oxygenation and ventilation in an acute lung injury model. Pediatr Pulmonol 2011; 46(1):67-74.

4. Vargas F, Saint-Leger M, Boyer A, Bui NH, Hilbert G. Physiologic effects of high-flow nasal cannula oxygen in critical care subjects. Respir Care 2015;60(10):1369-1376.

5. Chikata Y, Izawa M, Okuda N, Itagaki T, Nakataki E, Onodera M, et al. Humidification performance of two high-flow nasal cannula devices: a bench study. Respir Care 2014;59(8):1186-1190.

6. Groves N, Tobin A. High flow nasal oxygen generates positive airway pressure in adult volunteers. Aust Crit Care 2007;20(4):126131.

7. Parke R, McGuinness S, Eccleston M. Nasal high-flow therapy delivers low level positive airway pressure. Br J Anaesth 2009;103(6): 886-890.

8. Nishimura M. High-flow nasal cannula oxygen therapy in adults: physiological benefits, indication, clinical benefits, and adverse effects. Respir Care 2016;61(4):529-541.

9. Parke RL, McGuinness SP, Eccleston ML. A preliminary randomized controlled trial to assess effectiveness of nasal high-flow oxygen in intensive care patients. Respir Care 2011;56(3):265-270.

10. Hernández G, Vaquero C, González P, Subira C, Frutos-Vivar F, Rialp G, et al. Effect of postextubation high-flow nasal cannula vs conventional oxygen therapy on reintubation in low-risk patients: a randomized clinical trial. JAMA 2016;315(13):1354-1361. 


\section{PEEP EFFECT OF 3 HFNC DEVICES}

11. Frat JP, Brugiere B, Ragot S, Chatellier D, Veinstein A, Goudet V, et al. Sequential application of oxygen therapy via high-flow nasal cannula and noninvasive ventilation in acute respiratory failure: an observational pilot study. Respir Care 2015;60(2):170-178.

12. Papazian L, Corley A, Hess D, Fraser JF, Frat JP, Guitton C, et al. Use of high-flow nasal cannula oxygenation in ICU adults: a narrative review. Intensive Care Med 2016;42(9):1336-1349.

13. Karl-Josef Franke K-HR, Ulrike Domanski, Maik Schroeder, Sheng Feng, Stanislav Tatkov, Georg Nilius. Endotracheal pressure during nasal high flow in patients after long-term mechanical ventilation. Eur Respir J 2014;44(Suppl 58):4817.

14. Chanques G, Riboulet F, Molinari N, Carr J, Jung B, Prades A, et al. Comparison of three high flow oxygen therapy delivery devices: a clinical physiological cross-over study. Minerva Anestesiol 2013; 79(12):1344-1355.

15. Parke RL, McGuinness SP. Pressures delivered by nasal high flow oxygen during all phases of the respiratory cycle. Respir Care 2013; 58(10):1621-1624.
16. Kumar H, Spence CJ, Tawhai MH. Modeling the pharyngeal pressure during adult nasal high flow therapy. Respir Physiol Neurobiol 2015;219:51-57.

17. Parke RL, Eccleston ML, McGuinness SP. The effects of flow on airway pressure during nasal high-flow oxygen therapy. Respir Care 2011;56(8):1151-1155.

18. Corley A, Caruana LR, Barnett AG, Tronstad O, Fraser JF. Oxygen delivery through high-flow nasal cannulae increase end-expiratory lung volume and reduce respiratory rate in post-cardiac surgical patients. Br J Anaesth 2011;107(6):998-1004.

19. White FM. Fluid mechanics, 4th edition. New York: McGraw-Hill; 1998:462-466.

20. Messika J, Ben Ahmed K, Gaudry S, Miguel-Montanes R, Rafat C, Sztrymf B, et al. Use of high-flow nasal cannula oxygen therapy in subjects with ARDS: a 1-year observational study. Respir Care 2015; 60(2):162-169.

21. Demoule A, Rello J. High flow oxygen cannula: the other side of the moon. Intensive Care Med 2015;41(9):1673-1675.

This article is approved for Continuing Respiratory Care Education credit. For information and to obtain your CRCE

(free to AARC members) visit www.rcjournal.com

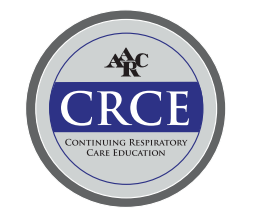

